\title{
Manuais de didática da história destinados à formação de professores e a constituição do código disciplinar da história no Brasil: 1935-1952
}

\section{Teacher manuals for History education and the constitution of the Brazilian History disciplinary code: 1935-1952}

\author{
Maria Auxiliadora Moreira dos Santos SCHMIDT ${ }^{*}$
}

Resumo: Neste trabalho, tomou-se como fonte para a investigação três manuais produzidos por professores de Didática da História e publicados, respectivamente, em 1935 (dois manuais) e 1952 (um manual), no contexto de duas reformas educacionais: a Reforma Francisco Campos (1931) e a Lei Orgânica do Ensino Secundário, Reforma Capanema (1942). Pesquisas recentes (CHOPPIN, 1998) têm indicado os manuais didáticos como elementos destacados da cultura escolar, situando-os como importantes e substanciais fontes para a História da Educação. Assim, tomou-se como objeto de análise manuais destinados à formação de professores que, devido à sua natureza e ao seu conteúdo, têm sido reconhecidos como diferentes dos manuais destinados aos alunos. Apreendidos como “textos visíveis do código disciplinar" (FERNANDEZ CUESTA, 1998), da Didática da História, estes manuais revelaram-se como indiciários de determinadas formas de pensar e do sentimento comum da prática profissional, bem como permitiram distinguir algumas evidências de maneiras pelas quais foram concebidas certas representações da História como saber escolar. Neste sentido, a análise dos três manuais permitiu sistematizar algumas questões, como certas concepções de História, bem como de um saber “técnico-prático” - ou um conjunto de princípios e estratégias de ensino. Isto permite sugerir que esta História com Pedagogia constituiu o fundamento de uma nova disciplina, a Didática da História, bem como levantar a hipótese de que muitos dos seus elementos passaram a contribuir para a constituição da representação da identidade profissional do professor de História no Brasil.

Palavras-chave: Manuais de Didática da História. Ensino de História. Código disciplinar da História.

\footnotetext{
* Doutora em História pela Universidade Federal do Paraná; Pós-Doutora em Didática da História pela Universidade Nova de Lisboa. Professora de Metodologia e Prática de Ensino de História da UFPR; professora e pesquisadora do Programa de Pós-Graduação em Educação-PPGE-UFPR. Universidade Federal do Paraná. Rua General Carneiro, 460, CEP-80010-200 - Curitiba-PR. Pesquisa financiada pelo CNPq. E-mail: dolinha08@uol.com.br.
} 
Abstract: In this study, the sources of investigation were three manuals produced by History education teachers and published in 1935 (two manuals) and 1952 (one manual), as a result of two educational reforms: the Francisco Campos Reform (1931) and The Secondary School Organic Law - Capanema Reform. Recent research (CHOPPIN, 1998), has shown that these didactic manuals are outstanding elements in school institutions, and are considered important and substantial sources in the History of Education. Thus the objects of analysis were manuals directed toward the education of teachers, which because of their nature and content, are recognized as different from the students' textbooks. Understood as the "visible texts of the History Education Disciplinary Code” (FERNANDEZ CUESTA, 1998), these manuals were revealed as indicative of determined ways of thinking and the shared sentiment of the professional practice. Also, they permitted the distinguishing of evidence of the ways in which certain representations of History were conceived as scholarly knowledge. Therefore, the analysis of these three manuals allowed for the systematization of questions, such as certain conceptions of History, as well as "a practicaltechnical” knowledge or a set of teaching principles and strategies. This information suggests that this History with Pedagogy constituted the foundation of a new subject, History Education, and possibly that many of its elements started to contribute to the development of the professional identity of the History teacher in Brazil.

Keywords: History education manuals. History teaching. History disciplinary code.

No Brasil, os estudos sobre publicações didáticas têm sido realizados por pesquisadores e especialistas das várias áreas do conhecimento. Na área específica do ensino de História estes trabalhos privilegiam, especialmente, determinados tipos de manuais, como a produção de manuais destinados a alunos (BITTENCOURT, 1993) e a produção editorial, conforme estudos de Munakata (1997).

As investigações em torno de manuais destinados especialmente a professores já existem e, apesar de serem em menor número, indicam a existência de novas possibilidades e recortes para análises, segundo atestam alguns trabalhos, como os de Monarcha (1997), Faria Filho (2000). No que se refere à área específica do ensino de História, foram encontrados poucos estudos feitos em manuais destinados à formação de professores, como os trabalhos de Schmidt (2005) e Freitas (2006), o que motivou a necessidade de ampliar as investigações, no sentido de levantar aspectos 
das publicações didáticas relacionadas ao ensino de História e destinadas a professores, com o objetivo de contribuir para uma reconstituição da relação ensino e aprendizagem e, portanto, da Didática da História no Brasil.

Na área do ensino de História, vários autores vêm contestando posições que pensam a Didática da História apenas como um conjunto de conhecimentos que tenta transformar, na prática, historiadores profissionais em professores da escola fundamental e média, perspectiva que tem acompanhado muitas concepções relacionadas com as disciplinas destinadas a ensinar como se ensina a história. No Brasil, a concepção de que estas disciplinas têm um caráter eminentemente “prático”, com base numa aplicação de técnicas e métodos de ensino aos conteúdos específicos da História, ainda é predominante, dando origem, inclusive, à criação de disciplinas como Didática da História do Brasil, Didática de História Medieval, Didática da História da América, sugeridas em recentes reformas curriculares dos cursos de História ${ }^{1}$.

No entanto, com base em estudos contemporâneos, pode-se constatar a existência de um domínio específico do conhecimento denominado Didática da História, o qual se inscreve nas interfaces da investigação entre a própria epistemologia da História, tomada como referência para a construção de categorias e metodologias de análise, e seu diálogo com outras ciências, situado "na encruzilhada de diversas ciências humanas entre as quais estão, por um lado, as que se ocupam tradicionalmente da aprendizagem e, por outro, as que constituem a base do conhecimento que se pretende ensinar” (PRATS, 2002, p.81).

Nesta direção, este trabalho procura entender a contribuição de manuais para a construção da Didática da História como um tipo de disciplina escolar, com um substrato próprio. O campo e o objeto de investigação da pesquisa são os manuais destinados à formação de professores, produzidos por profissionais do magistério, que se dedicaram ao ensino da Metodologia e Prática de Ensino de História, no Brasil, e que publicaram obras sobre as suas experiências, respectivamente em 1935 e 1952.

De um lado, este estudo insere-se no conjunto de reflexões sobre a história das disciplinas escolares (CHERVEL, 1990; CITRON, 1992; GOODSON, 1997), as quais têm apontado a necessidade de se entender os saberes escolares em sua especificidade, articulados às mudanças e continuidades inscritas nos ritmos próprios da longa duração, bem como relacionados com os contextos e estruturas das sociedades que os produziram.

De outro, o trabalho inscreve-se nos estudos sobre as didáticas das disciplinas ou didáticas específicas, temática que vem atraindo a atenção de pesquisadores educacionais, como atestam os trabalhos de Terrisse (2001), os quais indicam a constituição do campo das didáticas específicas baseando-se no conceito de "referência”. Nesse sentido, Moniot (2001) também assinala que a 
Manuais de didática da história destinados à formação de professores e a constituição do código disciplinar da história no Brasil: 1935-1952

construção do campo específico da didática da História é um fazer-se, instituído com base na referência à História dos historiadores, ao conceito de “transposição didática”, à própria constituição da História como disciplina escolar, bem como à ideia de prática social de referência, pressupondo, portanto, uma determinada cultura política e filosofia social.

Valendo-se destas perspectivas, aponta-se para a construção de um tipo de matéria escolar, isto é, de um conjunto de conhecimentos, ideias, valores, rotinas e práticas, que foram sendo sistematizadas em diferentes momentos históricos, e cuja principal finalidade passou a ser a constituição de uma base de referência sobre “como ensinar” a História e cujo destino é a formação inicial e/ou continuada de professores.

Historicamente, no Brasil, essa disciplina tem aparecido com várias denominações, tais como Didática da História, Metodologia do Ensino de História e Prática de Ensino de História, nos cursos de licenciatura destinados à formação do professor de História. Também recebeu o nome de Didática dos Estudos Sociais (incluindo Geografia e História), quando se destinava à formação de professores das séries iniciais ( $1^{\mathrm{a}}$. a $4^{\mathrm{a}}$. série).

O percurso instituído pelo ensino de História no Brasil, cujo marco institucional fundador é considerado o Regulamento de 1838 do Colégio D. Pedro II - o qual “determinou a inserção dos estudos históricos no currículo” (NADAI, 1993, p.146) -, permite concluir que houve um processo de construção do "código disciplinar da História no Brasil” que se inicia no século XIX, percorrendo as três primeiras décadas do século XX, até a Reforma Francisco Campos, de 1931. Até esse momento, segundo Hollanda (1957), os programas seguiam as orientações aprovadas pelos professores catedráticos e congregações do Colégio Pedro II, do Rio de Janeiro. A Reforma Francisco Campos, realizada pelo Governo Provisório instituído pela Revolução de 1930, por meio do Decreto $\mathrm{n}^{\circ}$ 19.890/1931, estabeleceu que os programas, bem como as instruções sobre os métodos de ensino de História, deveriam ser expedidos pelo recém criado Ministério da Educação e Saúde Pública. Instaura-se, assim, o processo de centralização e controle das diretrizes para o ensino de História por parte do Estado, inaugurando o processo de "consolidação do código disciplinar da História no Brasil”, inserido no quadro de desenvolvimento dos próprios modos de educar e de relações de poder da sociedade brasileira.

Nesse sentido, é viável afirmar que o período da segunda metade do século XIX, até 1931, se caracteriza pelo movimento de construção do código disciplinar da história no Brasil, como assinala o trabalho de Nadai (1993), estudo clássico sobre a trajetória do ensino de história em nosso país. A autora indica alguns matizes que delinearam o que pode ser considerado como 
elementos do código disciplinar da História na sociedade brasileira no período. Entre eles estão algumas experiências particularizadas de ensino, a presença de certos conteúdos de História em algumas séries da escola e a produção de manuais didáticos destinados a alunos. Ademais, o processo de construção da História como disciplina escolar insere-se, a partir da segunda metade do século XIX, no próprio movimento de construção e consolidação do Estado Nacional, no qual se destacam os embates entre monarquistas e republicanos e a necessidade de definição de uma identidade nacional. A proclamação da República, em 1889, explicita a importância da História, principalmente a História do Brasil, para a formação de um determinado tipo de cidadão. Este processo consolida-se com a Revolução de 1930, no bojo do movimento de defesa da importância da educação para a formação do cidadão e para o desenvolvimento do país.

Tendo como referência esse contexto, a investigação realizada nos três manuais abrange o segundo período, que pode ser designado como o da Consolidação do Código Disciplinar da História (1931-1952), em que os conteúdos da História foram introduzidos oficialmente, como proposta curricular obrigatória e única para as escolas de todo o país, a partir da Reforma Francisco Campos, de 1931. É justamente neste período que os manuais destinados à formação do professor de História passam a ser editados e publicados no Brasil, de forma sistemática.

Entre as bandeiras de luta dos educadores brasileiros, deste e dos períodos subsequentes até a década de 1950, estavam: a necessidade da expansão da escola, especialmente a escola pública; a formação profissional dos novos mestres e a renovação pedagógica. Este tripé - expansão da escola, formação de professores e renovação pedagógica -, em função das demandas nacionais, embasa e estimula a produção e a difusão de uma literatura específica, destinada à formação renovada de professores. Estas publicações consolidar-se-ão como documentos importantes para orientação das práticas pedagógicas escolares, de modo geral, e de História, em particular.

Nesta direção, a pesquisa identificou, no período entre 1930-1952, duas variantes em que a didática da História esteve presente, sob a forma de manuais destinados a professores. A primeira delas refere-se ao conteúdo da Didática da História como parte dos manuais de Didática Geral, seja de autores brasileiros, seja de autores estrangeiros traduzidos para o português. A outra, diz respeito a manuais específicos de Didática da História, produzidos por professores de escolas primárias, secundárias, da Escola Normal e da Universidade, que apresentam, de forma explícita, suas opções por concepções de História.

Além do recorte temporal, a pesquisa delimitou, também, a escolha do tipo de manual a ser analisado, a qual se ateve aos manuais produzidos por professores que ministravam a disciplina específica da Didática da História nos diferentes níveis de ensino e que podem ser caracterizados como manuais específicos de Didática da História. Os manuais utilizados como fontes foram 
Manuais de didática da história destinados à formação de professores e a constituição do código disciplinar da história no Brasil: 1935-1952

publicados em dois momentos significativos para o ensino de História no Brasil. O primeiro deles é em 1935, durante o processo de implementação da Lei Francisco Campos (de 1931), que tornava obrigatório o ensino de História na escola secundária, inclusive a História do Brasil. Neste período, foram publicados dois manuais:

Jonathas Serrano - Como se ensina a história. São Paulo: Editora Cia. Melhoramentos de São Paulo, 1935. O autor já havia publicado um manual da mesma natureza, em 1917, dirigido a professores da escola primária. Era professor do Instituto de Educação e do Colégio Pedro II, do Rio de Janeiro. Produziu, também, vários manuais didáticos de história geral e do Brasil, destinados a alunos.

Murillo Mendes - A História no Curso Secundário. Monografia para o concurso da cadeira de Metodologia do ensino secundário, do Instituto de Educação, da Universidade de São Paulo. São Paulo: Gráfica Paulista, 1935. O autor era secretário-geral da reitoria da Universidade de São Paulo.

O segundo momento refere-se à análise do terceiro manual, que foi publicado após a promulgação do Decreto-Lei n ${ }^{\circ}$. 4.244, de 1942 - Reforma Gustavo Capanema e da Portaria 1.045, da Reforma da Escola Secundária, de 1951. Trata-se do livro da professora Amélia Americano Franco Domingues de Castro, Princípios do Método no Ensino da História. Essa obra refere-se à sua tese de doutoramento apresentada à cadeira Didática Geral e Didática Especial, da Faculdade de Filosofia, Ciências e Letras da Universidade de São Paulo. São Paulo: Universidade de São Paulo, Faculdade de Filosofia, Ciências e Letras, Boletim 138, Didática Geral e Especial 1, 1952. A autora foi professora de Prática de Ensino de História da USP.

A opção pela análise de manuais tem como referência o pressuposto de que determinados objetos contribuem para materializar as disciplinas, entre eles o manual didático. Trata-se de um tipo de objeto da cultura escolar, produzido fora da escola, mas destinado ao uso em sala de aula, caracterizando-se como um dos elementos do contrato didático, porque “um protocolo preside o seu uso, o qual é raramente ensinado, mas frequentemente enunciado, e que aluno descobrirá progressivamente” (DEVELAY, 1992, p.33). Da mesma forma, os objetos utilizados no ensino de uma disciplina mudam, ao mesmo tempo que a sua matriz disciplinar muda. É neste sentido que pode se falar da importância do manual didático na construção da história da Didática da História, uma disciplina que foi sendo instituída nas e valendo-se das experiências realizadas nos cursos de formação de professores, acompanhando o próprio processo de pedagogização da História no Brasil. 
Uma importante questão é elucidar as principais características deste tipo de publicação. De modo geral, os manuais destinados à formação de professores têm sido incluídos no conjunto de publicações que "são tanto produzidos quanto impressos tendo em vista o mercado escolar" (BATISTA, 2000, p.542), remetendo, portanto, à necessidade de identificá-los no movimento de construção do processo de escolarização.

Segundo Briand/Chapoulie (1993), este processo é um fenômeno relacionado à experiência própria da instituição escolar e com os sujeitos nela envolvidos, bem como inserido na dinâmica das articulações entre as instituições escolares e determinados projetos e propostas políticas. Ao mesmo tempo, esse movimento é um processo paulatino de produção de referências sociais, de uma cultura escolar, tendo a escola ou a forma escolar de socialização e transmissão de conhecimentos como eixos articuladores de sentidos e significados, ao qual se dá o nome de escolarização do social. Nesta perspectiva é que se explicitam questões que dizem respeito às relações entre escola, cultura e ensino, as quais requerem a superação de concepções reprodutivistas da escolarização, bem como a particular importância da noção de cultura, pois ela permite articular, descrever e analisar os elementos-chave que compõem o fenômeno educativo, incluindo-se, entre eles, os manuais didáticos (FARIA FILHO, 2000).

Assim, os manuais destinados aos professores pertencem à cultura escolar e à cultura da escola, sendo produtos e produtores de conhecimentos escolares, instituidores de modos de fazer ou de construir a escolarização, bem como construtores de identidades pessoais e profissionais. Enquanto referenciadores e normatizadores de práticas pedagógicas escolares, eles contribuíram e contribuem para urdir e dinamizar a complexa trama do cotidiano escolar. Neste sentido, estão identificados com a construção da forma escolar, a qual permite recuperar a formação do professor destinado ao ensino de História no movimento do "pensar a mudança” no processo de escolarização brasileiro (VINCENT; THIN; LAHIRE, 2001, p.10).

Eles também podem ser definidos com base em sua principal característica, isto é, pelo tipo de leitor a quem, prioritariamente, se destinam - os professores, na “forma de manuais de didática geral ou didática especial,( que propunham métodos e atividades de ensino de alguma disciplina), os livros didáticos exclusiva ou prioritariamente para o professor.” (BATISTA, 2000, p.551).

A opção pela pesquisa em manuais destinados à formação de professores de História significa, também, tratar este objeto valendo-se dos marcos definidores iniciais, isto é, como manuais didáticos relacionados ao processo de escolarização, constitutivos da cultura escolar e destinados à formação didático-pedagógica dos professores, em determinado período e contexto da sociedade brasileira. O fato de proporem métodos e atividades de ensino da disciplina História 
Manuais de didática da história destinados à formação de professores e a constituição do código disciplinar da história no Brasil: 1935-1952

indica a necessidade de explicar o que se entende pelo conjunto de conhecimentos veiculados por estes manuais, ou o tipo de saberes constitutivos destas publicações.

Em primeiro lugar, é preciso distingui-los dos manuais cujo conteúdo principal é o conhecimento histórico propriamente dito: conteúdos de História Antiga, Medieval, Moderna, Contemporânea e História do Brasil, tratados didática e graficamente com a finalidade do ensino/aprendizagem da História pelos alunos. Os manuais de Didática da História trazem uma gama de conhecimentos que podem ser incluídos nos saberes e práticas próprios da prática de sala de aula de História. Eles são destinados a uma introdução formal para o ensino de História nas escolas, exercendo a função de mediação entre a História como disciplina acadêmica e os modos de ensinar o conhecimento histórico na sala de aula. Segundo Rüsen (1987), a natureza destes conteúdos é guiada pelas necessidades da formação dos professores para o ensino de História, cujo processo pode ocorrer em dois níveis e constituem o substrato da disciplina Didática da História.

O primeiro nível é puramente prático e de acordo com os métodos de ensino de História na sala de aula. Trata-se de um relato influenciado pela pedagogia - é falar e ensinar como fazer. Rüsen (1987) chama este aspecto de Metodologia do ensino de História. O outro é teórico, pois focaliza as condições e as necessidades básicas do ensino e aprendizagem da História. Trata-se da discussão da História em relação a outros conhecimentos com os quais está comprometido o fenômeno do ensino e aprendizagem. Por exemplo, as ciências sociais que investigam as condições sociais do ensino e da aprendizagem e, naturalmente, com os próprios historiadores os quais investigam a História como sujeito principal do discurso. Neste nível, diz o autor, "se estabelece os objetivos e formas da educação histórica, a partir de um determinado contexto político, social, cultural e institucional. A metodologia do ensino de História estabelece os significados práticos através dos quais estes objetivos podem ser alcançados” (RÜSEN, 1987, p.277).

Os trabalhos de Rüsen (1987) indicam que os manuais destinados aos professores referem-se a um determinado conhecimento escolar, um tipo especial de saber, ou seja, a História como matéria a ser ensinada, que pode ser explicada pela sua inserção numa larga tradição social inventada, não de uma só vez, e recriada que pode ser denominada de “código disciplinar”, ou seja “uma tradição social que se configura historicamente e que é composta de um conjunto de ideias, valores, suposições e rotinas, que legitimam a função educativa atribuída à História e que regulam a prática de seu ensino” (FERNÁNDEZ CUESTA, 1998, p. 8-9). Ademais, na perspectiva de Fernandez Cuesta, do “código disciplinar”, também fazem parte os "textos visíveis”, como os currículos, os discursos, as leis, as formas de regulação, bem como os “textos invisíveis", como as 
práticas e contextos escolares que constituem parte do projeto educacional de cada época, em cada sociedade.

Nesta perspectiva, tais manuais podem ser vistos como constitutivos do "código disciplinar” da História e, assim, analisados em duas dimensões. A primeira diz respeito à ideia da construção do código disciplinar como uma tradição que se configura historicamente em uma larga duração, com base na relação que se estabeleceu entre a edificação da história como disciplina escolar e a dinâmica da educação brasileira, como as reformas educacionais realizadas.

A segunda incita à análise dos manuais tomando por base a busca de características do “código disciplinar”, a qual coloca em relevo a complexa problemática das relações entre conhecimento científico e conhecimento escolar, pois os livros de texto são uma parte da "tradição seletiva” que, “em virtude de una ação recontextualizadora efetuada por vários agentes sociais, converte o saber acadêmico em conhecimento escolar legítimo, transformando a ciência que se faz na ciência que se ensina” (FERNANDEZ CUESTA, 1998, p.102). Neste sentido, a análise dos manuais pode elucidar aspectos da "transposição didática” (CHEVALLARD, 2000) relacionados à construção dos modos de ensinar a História, enunciados pelos autores com base em sua própria cultura experiencial. Alguns autores, como aqueles que produzem os manuais de Didática Especial, organizam esta transposição valendo-se de suas experiências como educadores ou especialistas em educação. Outros sistematizaram seus enunciados baseados em suas experiências em salas de aula, como especialistas em determinada disciplina.

Desde o momento de sua introdução como elemento constitutivo do código disciplinar da História, estes manuais já apresentam o que Fernandes Cuesta (1998) chama de "história com pedagogia”, porque ressaltam e valorizam aspectos pedagógicos como fundamentais para um ensino cujo objetivo era formar verdadeiros cidadãos. Neles, a interação com o conteúdo específico da História foi mediada por elementos pedagógicos e psicológicos e o conteúdo passou a ser visto muito mais em função do seu interesse e adequação aos alunos.

Neste aspecto, é importante destacar que os três manuais analisados dedicam uma parte às reflexões sobre a História como ciência e outra parte aos aspectos metodológicos do seu ensino. A preocupação com os aspectos metodológicos no ensino de História já existia na obra de Jonathas Serrano, publicada em 1917, mas foi a Reforma Francisco Campos, de 1931, que apresentou, pela primeira vez, nas propostas das diferentes disciplinas, incluindo a História, a grande novidade das Instruções Metodológicas.

A presença das Instruções Metodológicas na Reforma Francisco Campos é demonstrativa da consolidação da História como disciplina escolar obrigatória para todas as escolas. Elas enfatizam a renovação metodológica como o caminho para a construção de um ensino necessário à formação do 
Manuais de didática da história destinados à formação de professores e a constituição do código disciplinar da história no Brasil: 1935-1952

cidadão mais crítico, uma expectativa da luta dos educadores neste período, bem como são indiciárias da presença das ideias da Escola Nova no Brasil. Entre as ideias que influenciam inovações aos autores dos manuais analisados, destaca-se a presença prioritária do pensamento de John Dewey.

A obra de Dewey, L'école et l'enfant, apesar de não ter tradução em português, foi sempre referenciada e algumas ideias foram incorporadas pelos autores que escreveram os manuais analisados. Algumas delas tornaram-se referência para o ensino de História, particularmente no destaque que Dewey dá para o fato de que não se pode tomar a História como o estudo dos fatos do passado, pois esta perspectiva dificulta a presença deste conteúdo na escola primária. Nessa mesma obra, o autor enfatiza a importância de se ensinar a História como "une explication des forces et des formes qui se présentent dans la vie sociale. Cette vie sociale est l'atmosphere que nous respirons: le présent et le passe s’y enchevêtrent indissolublement.” (DEWEY, 1913, p.119)².

A relação entre o presente e o passado no ensino de História, assumida enfaticamente por Dewey, passou a ser o princípio metodológico fundamental a ser observado pelos professores, autores dos manuais. Ademais, o princípio de se apresentar a História como algo em movimento e não como um acúmulo de informações sobre o passado tornou-se o ideal a ser seguido em sala de aula. Neste sentido, Dewey foi pioneiro em propor a inserção de conteúdos relacionados à maneira de viver dos povos como uma forma de atrair o interesse das crianças e de fazê-las simpatizar com o passado e penetrá-lo por meio de sua imaginação. Pode-se afirmar que, neste aspecto, ele foi pioneiro na defesa do uso da empatia e da imaginação histórica como componentes dos processos de ensino e aprendizagem da História.

É nesta mesma obra que Dewey aponta a temporalidade como uma das grandes dificuldades no ensino e aprendizagem da História, produzindo o conflito entre a interpretação lógica e a interpretação psicológica da História. Como contribuição aos programas de História para a escola primária, ele reconhece algumas fases ou períodos. De início, afirma o autor, a história deve se referir ao sentido local e cronológico da palavra, para dar à criança a intuição das diversas atividades sociais, estudando as ocupações típicas das pessoas de sua localidade e de seu país. Mais tarde, ela seguirá estudando a evolução das invenções, dos grandes movimentos migratórios, das explorações e das descobertas que abriram o mundo inteiro à intervenção humana (DEWEY, 1913, p.119-128).

A perspectiva do ensino de História a partir da situação social com os seus problemas pode ser encontrada na obra Democracia e Educação, nas reflexões de Dewey sobre o significado da 
Geografia e da História. Nesta mesma obra, o autor defende explicitamente a valorização do ensino da história econômica, em detrimento da história política, pois “A história econômica é mais humana, mais democrática e, por isso, de influxo mais liberal do que a história política. Ella não se preoccupa com a ascensão e a queda de principado e poderes, mas com o desenvolvimento da verdadeira liberdade, por meio do domínio da natureza effectuado pelo homem commum, que é para quem existem os poderes e os principados”. (DEWEY, 1936, p. 172). Ao criticar o ensino centralizado na história política, Dewey antecipa um movimento de renovação do ensino de História que, lentamente, vem chegando às escolas brasileiras, seja pelas sucessivas propostas curriculares, seja pelos manuais de Didática da História.

Muitas dessas inovações foram sugeridas no manual Como se ensina a História, de Jonathas Serrano, publicado em 1935. Este manual faz parte do conjunto de publicações da "Biblioteca da Educação”, organizada por Lourenço Filho, e essa coleção “é contemporânea e caudatária de outros empreendimentos editoriais semelhantes, implementados tanto no Brasil como em outros países da América e Europa” (MONARCHA, 1997, p.31). Com esta obra, Serrano consolidou sua posição como intelectual identificado ao horizonte social em que se inscreve a perspectiva do "otimismo pedagógico”. No momento da sua produção, era professor do Colégio Pedro II e Membro do Instituto Histórico e Geográfico e este livro pertence à já referida Biblioteca de Educação, volume número 25.

Ao contrário do que foi sugerido nas Instruções Metodológicas da Reforma Francisco Campos, do ponto de vista do conteúdo a ser ensinado, o livro de Serrano contém uma severa crítica aos conteúdos propostos pela Reforma Curricular Francisco Campos, de 1931. O significado desta Reforma no contexto pós-Revolução de 1930 já foi analisado por Abud (1993), para quem a História era tida como disciplina que, por excelência, formava os estudantes para o exercício da cidadania e seus programas incorporavam essa concepção.

Com relação à Reforma Francisco Campos, de 1931, Serrano (1935, p. 95) afirma que ela seria absolutamente irrealizável, “dir-se-ia que os programmas dessas séries foram elaborados por quem jamais esteve em contacto com a realidade viva de classes secundarias do nosso meio. Número excessivo de pontos”. Note-se a preocupação do autor com a adequação do currículo ao desenvolvimento dos alunos e aos seus interesses. Neste sentido, a obra Como se ensina a História reserva vários capítulos às questões metodológicas, aprofundando questões já explicitadas em outras obras de Serrano.

A preocupação com a renovação metodológica no ensino de História também está presente na obra de Murillo Mendes. Esse autor dedica grande parte de suas reflexões à necessidade da renovação do ensino de História, preocupado que está com a sua adequação aos ideais e interesses 
Manuais de didática da história destinados à formação de professores e a constituição do código disciplinar da história no Brasil: 1935-1952

da juventude. Ao contrário de Serrano, para quem a Reforma Francisco Campos, apesar de apontar as inovações metodológicas, é passível de crítica, Mendes considera essa proposta como inovadora em todos os sentidos. No entanto, assim como Serrano, ele dedica uma grande parte do seu livro às reflexões sobre o conhecimento histórico. Segundo Freitas, em sua obra A história no curso secundário (1935, p. 45), Mendes é um americanista bastante elástico e, sobre esse aspecto, fez par com Dewey (FREITAS, 2006, p.243).

Já com relação ao manual publicado por Castro (1952), uma novidade a ser destacada é a forma pela qual ela admite a diferença entre a Didática Geral - o estudo das diferentes técnicas didáticas particulares aplicáveis nas situações em que se defrontam professores e alunos, ligado com as considerações gerais que as explicam e fundamentam, bem como os diversos modos de proceder que são utilizados na aprendizagem, que obedecem a certos princípios mais gerais que constituem o método pedagógico -, e a Didática Específica, a qual considera o método pedagógico em função de uma determinada matéria. A proposta do seu livro é: - estabelecer os princípios básicos referentes à natureza da História; - estudar os princípios gerais do método pedagógico, com base no qual se busca as finalidades da ação educativa e as características próprias do educando, para as diretrizes da orientação didática; - desenvolver os processos didáticos particulares nos quais se encontram os princípios fundamentais já explicitados. Assim, para Castro, (1952), existe uma Didática Específica da História, a qual é constituída pelos princípios que definem a natureza da História enquanto ciência e pelos princípios de natureza psicopedagógica, como o método de ensino, os objetivos educacionais e a concepção de educando. Esta preocupação está presente em toda a estrutura do seu livro.

Já no primeiro capítulo da segunda parte, a autora procura explicitar a relação entre a história como conhecimento específico e os outros conhecimentos que interferem no seu ensino, tais como a psicologia, a pedagogia e a sociologia, com o intuito de definir o método e as finalidades do ensino. Em primeiro lugar, procura definir o que entende por método - ou seja, um conjunto de meios ou os processos empregados para atingir o objetivo visado. Busca também distinguir método de técnica, processo ou artifício de ensino. A técnica é uma fase do método, que é a aplicação prática de certos princípios pedagógicos. Existem também as técnicas didáticas para aplicação e uso dos instrumentos de ensino (quadro de giz, cinema, etc.). Os métodos derivam de determinada doutrina filosófica ou psicológica, como o método do pensamento reflexivo de Dewey, o método dos passos formais de Herbart e dos projetos de Kilpatrick. 
A autora baseia-se nos princípios da teoria da atividade do educando, de John Wynne, os quais pressupõem: - uma atitude ativa da escola perante a organização da sociedade o que exige a formação de hábitos de iniciativa, participação, cooperação, crítica e pesquisa, no educando; o desenvolvimento da interação entre o indivíduo e o meio, que exige o ajustamento progressivo do educando ao meio e a harmonia entre os indivíduos e a sociedade; além da consideração do indivíduo como um todo orgânico. Baseia-se também nos princípios da teoria da educação funcional de Claparede, os quais indicam o pressuposto da atividade como atitude inerente ao educando e pressupõem a educação como o desenvolvimento interno do indivíduo e a inteligência como um processo de adaptação a situações difíceis. Em todos os momentos, ela procura a aplicabilidade destes princípios no ensino de História, fazendo uma apropriação explícita do pensamento de Dewey, para afirmar que é impossível considerar um método de ensino como separado da matéria à qual se aplica, bem como do objeto ao qual se aplica. Assim, afirma que entende a História como um conhecimento que estuda as sociedades humanas e sua evolução, para se compreender o presente e “a continuidade histórica entre passado e presente, constituindo o material com o qual trabalhará o professor - material a ser ainda considerado em suas finalidades e em suas possibilidades de assimilação por parte do educando” (CASTRO, 1952, p.49).

Então, o que seria próprio da História e dos outros conhecimentos? Segundo o que Castro propõe em sua obra, há um conjunto de conhecimentos gerais, psicológicos, sociológicos e pedagógicos que esclarecem o mecanismo mental da aquisição dos conhecimentos, da formação de hábitos e atitudes, motivos de ação, etc. Estes constituem os princípios que devem dirigir a ação pedagógica em qualquer circunstância, inclusive na metodologia específica de cada disciplina e que formam a tríade essencial: matéria, fins, meios. Também confere um destaque especial ao educando que, em sua opinião, é o centro polarizador das atenções da Didática da História. Para a autora, a finalidade do ensino de História deve levar em consideração o desenvolvimento do educando e a adaptação do indivíduo à sociedade.

Ainda de acordo com Castro, a melhor proposta para o ensino de História é aquela adequada à realidade das escolas e exige uma mudança na mentalidade dos professores que, "com felizes exceções, apegam-se a processos rotineiros e destituídos de objetivos. A reforma do ensino de história depende exclusivamente de ser ela compreendida, aceita e praticada pelos professores, com entusiasmo e carinho”. (CASTRO, 1952, p.50).

Explicitamente, a autora faz referência ao Decreto-lei $n^{\circ}$. 4.244, de 9 de abril de 1942, do Ministro Gustavo Capanema, destacando as finalidades do ensino secundário, propostas no artigo $1^{\mathrm{o}}$, quais sejam: 
[...] formar, em prosseguimento da obra educativa do ensino primário, a personalidade integral dos adolescentes; acentuar e elevar, na formação espiritual dos adolescentes, a consciência patriótica e a consciência humanística; dar preparação intelectual geral que possa servir de base a estudos mais elevados de formação especial. (DECRETO-LEI, 1942, p. 209).

Castro também concorda com a concepção de jovem inscrita na lei, em que estes são considerados como adolescentes, seres imaturos, cuja personalidade está em formação.

No subtítulo, no qual analisa os Objetivos do Ensino de História, começa anunciando a importância de se diferenciar a história ciência da história escolar. Os objetivos de cada uma, apesar de não serem diferentes, precisam ser considerados em suas especificidades, pois, "para a primeira o fim está dentro do próprio conhecimento e para a secunda o fim está no educando e seu desenvolvimento”. (CASTRO, 1952, p.54). Ela afirma sua posição de que o principal propósito do ensino de História nas escolas públicas brasileiras é treinar cidadãos e não produzir historiadores científicos, o que revela, de sua parte, uma consciência acerca da especificidade do conhecimento histórico escolar e de uma disciplina que tem a responsabilidade de transmitir este tipo de conhecimento.

Ao mesmo tempo, vemos sua preocupação em indicar a relação entre o ensino e os modos de educar de cada sociedade, quando diz que os objetivos da educação, em cada país, determinam a seleção das matérias a ensinar e a discriminação dos programas, bem como seu compromisso com os interesses e as realidades dos jovens estudantes da escola secundária, como atesta a pesquisa que fez sobre este tema. Esta pesquisa foi realizada em 1951, num universo de 428 alunos (377 amostras), questionando sobre se eles gostavam de história e que acontecimentos históricos mais lhes agradavam.

De acordo com Castro, 88,5\% do total responderam afirmativamente. Este resultado possibilitou-lhe afirmar que os adolescentes estão aptos a aprender história, particularmente porque têm facilidade de desenvolver a imaginação, quesito fundamental para a aprendizagem do passado; além da capacidade de reflexão, ou de raciocinar (analisar, sintetizar, deduzir, induzir, perceber relações, julgar e extrair conclusões). Outra capacidade inerente ao adolescente, conforme a autora, é a do desenvolvimento da curiosidade - eles tudo indagam, tudo querem saber, têm atração pelo novo e pelo exótico. Em sua opinião, uma dificuldade a ser superada pelo professor, é a atração que os adolescentes têm pelas guerras, lutas e conquistas, mas, segundo ela, estes interesses podem ser facilmente sublimados. Ao mesmo tempo, Castro aponta que novos interesses devem ser despertados e criados nos adolescentes, tais como o interesse pela evolução da civilização, pela 
continuidade e inter-relação entre passado e presente; pela vida social em geral (usos, costumes, línguas, crenças etc.); pela vida cultural em todos os seus aspectos; pelas relações entre os homens e o meio, gêneros de vida, descobertas etc.; pela vida política nacional e internacional, e pela vida econômica em geral.

Uma das questões que também deve ser destacada no manual de Castro, é o fato de a autora admitir uma problemática que ainda persiste na formação do professor de História, qual seja a dicotomização entre a formação do especialista e a formação pedagógica. Em sua opinião, para superar esta questão é necessário levar em conta a posição do especialista, o qual possui uma visão completa sobre determinado corpo de conhecimentos logicamente organizados e a posição do aluno, para quem a matéria é o desconhecido a explorar. A organização lógica do conhecimento histórico é a meta e não o ponto de partida do ensino. Este ponto de partida deve ser o ponto de vista do aluno.

Como assevera Fernandez Cuesta (1997; 1998), o “código disciplinar” da Didática da História foi se consolidando com base em relações que se estabeleceram entre marcos contextuais, perspectivas das ciências e uma determinada prática escolar desenvolvida em cursos de formação de professores. Os manuais analisados evidenciam, assim, alguns elementos originais para a análise do “código disciplinar” de uma disciplina que nasceu nos espaços destinados à formação de professores, como o Instituto de Educação e a Faculdade de Educação, com alguns elementos que definem a sua natureza específica. Entre eles, podem ser citados a forte relação com as diretrizes educacionais propostas pelo Estado, o diálogo com outras ciências, como a psicologia e a sociologia, bem como chamada “pedagogização da História”. Essa “pedagogização” revestiu-se, principalmente, pela incorporação de aspectos relacionados aos métodos e técnicas de ensino e aos estudos referentes à personalidade e psicologia do educando, importados da disciplina Didática Geral, indicando a existência de um novo tipo de conhecimento ou de uma didática específica, cujos conteúdos destinam-se a “ensinar a ensinar” a História.

A forma da "transposição didática” do conhecimento histórico em conhecimento histórico escolar, que constituiu o substrato de conteúdos próprios desta nova disciplina, conforme sugerido pelos manuais investigados, não levou em consideração, neste momento, o fato de que a concepção de aprendizagem, bem como o método de ensino pressupõem uma relação intrínseca com o método e a filosofia da própria ciência, a qual delimita, não somente os objetivos e finalidades do ensino, mas também a sua forma de aprender e, portanto, de ensinar. Pelo contrário, a transposição didática do conhecimento histórico em conhecimento escolar pautou-se, sobretudo, na imposição dos aspectos psicológicos e pedagógicos, ocorrendo o que Rüsen (1987) chamou de afastamento da 
Manuais de didática da história destinados à formação de professores e a constituição do código disciplinar da história no Brasil: 1935-1952

História e de sua função de formação didática. Esse pode ser um dos fatores que afastaram tanto a teoria da prática, o ensino da pesquisa e “a história dos professores da história dos historiadores”.

\section{Notas:}

\footnotetext{
${ }^{1}$ Sobre essa questão, ver o trabalho de URBAN, Ana Claudia. Didática da História: percursos de um código disciplinar no Brasil e na Espanha. Tese (Doutorado em Educação) - Universidade Federal do Paraná, Curitiba, 2009.

2 “Como uma explicação das forces e das formas que estão presentes na vida social. Esta vida social é a atmosfera que nós respiramos: o presente e o passado se misturam, indissoluvelmente” (Tradução da autora).
}

\section{Referências:}

ABUD, K. O ensino de História como fator de coesão nacional: os programas de 1931. Revista Brasileira de História. Dossiê: Memória, História, Historiografia. São Paulo: Marco Zero/Anpuh/CNPq, n. 25/26, p. 163-174, 1993.

BATISTA, A. A. G. Um objeto variável e instável. Texto, Impressos e Livros Didáticos. In: ABREU, M. (Org.). Leituras, História e História da Leitura. Campinas: Mercado de Letras; ALB/São Paulo: FAPESP, 1999, p. 529-575.

BITTENCOURT, C. M. F. Livro didático e conhecimento histórico: uma história do saber escolar. 1993. Tese (doutorado em História) - Faculdade de Filosofia, Letras e Ciências Humanas, Universidade de São Paulo, São Paulo, 1993.

BRIAND, J. P.; CHAPOULIE, J. M. L'institution scolaire et la scolarization: une perspective d'ensemble. Revue Française du sociologie, XXXIV, p. 3, 1993.

CASTRO, A. A. F. D. de. Principios do método no ensino da historia. São Paulo: USP-Fac. Filosofia, Ciencias e Letras, 1952.

CHEVALLARD, Y. La transposición didáctica. Del saber sabio al saber enseñado. Buenos Aires: Aique, 2000.

CHERVEL, A. História das disciplinas escolares: reflexões sobre um campo de pesquisa. In. Teoria \& Educação. Porto Alegre: Pannomica, 1990.

CITRON, S. La historia y las tres memorias. In: PEREYRA, M. (Org.). La historia en el aula. Madrid: ICE de la Universidad y la Laguna, 1992.

CHOPPIN, A. Las políticas de libros escolares en el mundo: perspectiva comparativa e histórica. In. SILLER, J. P.; GARCIA, V. R. (Coord.). Identidad en el imaginário nacional. Reescritura y enseñanza de la historia. Inst. C.S. Humanidades, BUBA, Puebla El Colegio de San Luis, A.C./ Inst. Georg-Eckert, Braunscheweig, Alemania, 1998, p. 169-180.

DECRETO DE LEI n ${ }^{\circ} 4.244$ de 9 de abr. 1942. 
DEVELAY, M. De l'apprentissage à l'enseignement Pour une épistémologie scolaire. Paris: E S F Editeur, 1992.

DEWEY, J. L'école et L'enfant. Paris: Declachaux \& Niestlé, 1913.

DEWEY, J. Democracia e Educação. Breve Tratado de Philosophia de Educação. São Paulo: Companhia Editora Nacional, 1936.

FARIA FILHO, L. M. (Org.) Modos de ver. Formas de escrever. Estudos de História da Leitura e da escrita no Brasil. Belo Horizonte: Autêntica, 1998.

FREITAS, I. Histórias do ensino de história no Brasil. São Cristovão: Editora UFS; Aracaju: Fundação Oviêdo Teixeira, 2006.

FERNANDEZ CUESTA, R. Clio en las aulas. La enseñanza de la Historia en España entre reformas, ilusiones y ruinas. Madrid: Akal, 1998.

FERNANDEZ CUESTA, R. Sociogénesis de una disciplina escolar: la Historia. Barcelona: Ediciones Pomares-Corredor, 1997.

GOODSON, I. E. A. A construção social do curriculo. Lisboa: Educa, 1997.

HOLLANDA, G. de. Um Quarto de Século de Programas e Compêndios de História para o Ensino Secundário Brasileiro 1931-1956. Rio de Janeiro: INEP - Instituto Nacional de Estudos Pedagógicos/MEC - Ministério da Educação e Cultura, 1957.

MENDES, M. A historia no curso secundário. São Paulo: Graphica Paulista, 1935.

MONARCHA, C. L. F. Outros aspectos, Mesma obra. Campinas: Mercado de Letras; Marília: UNESP, 1997.

MUNAKATA, K. Produzindo livros didáticos e paradidáticos. 1997. Tese (Doutorado em História e Filosofia da Educação). PUC, São Paulo, 1997.

MONIOT, H. La question de la référence en didactique de l'histoire. In: TERRISE, A. Didactique des disciplines. Les références au savoir. Bruxelles: De Boeck Universitaire, 2001, p.65-77.

NADAI, E. O ensino de história no Brasil: trajetória e perspectivas. In: Revista Brasileira de História. Dossiê ensino de História. São Paulo: Marco Zero/ANPUH/CNPq, n.25/26, p.143-162. set./92; ago/93.

PRATS, J. Hacia una definicion de la investigación en didáctica de las ciencias sociales. In: Revista Enseñanza de las ciencias sociales. Revista de investigación. Institut de ciencies de l Educacio de la Universitat Autónoma de Barcelona, n.1, p.81-89, mar. 2002.

RÜSEN, J. The didactics of history in west Germany: Towards a new self-awareness of historical studies. History and theory, Wesleyan University, vol. XXVI, n.3, p. 275-286, 1987.

SERRANO, J. Como se ensina a historia. São Paulo: Cia. Melhoramentos, 1935. 
SCHMIDT, M. A. M. S. História com Pedagogia: a contribuição de Jonathas Serrano na construção do código disciplinar da História no Brasil. Revista Brasileira de História. Produção e divulgação de saberes históricos e pedagógicos. São Paulo: ANPUH/FAPESP, n.48, p. 189-212, ago. 2004 jul. 2005.

TERRISE, A. La referente en question. In. TERRISE, A. (Ed.). Didactique des disciplines. Les references au savoir. Bruxelles: De Boeck Université, 2001, p.7-14.

URBAN, A. C. Didática da História: Percursos de um Código Disciplinar no Brasil e na Espanha. Tese de Doutorado. Curitiba: UFPR/Programa de Pós-Graduação em Educação, 2009.

VINCENT, G.; LAHIRE, B.; THIN, D. Sobre a história e a teoria da forma escolar. Educação em Revista, Belo Horizonte, n.33, p.7-47, jun. 2001.

Recebido em 16/05/2011

Aprovado em 17/09/2011. 